\title{
The hospice as a learning environment: A follow-up study of a death education intervention that involved high-school students and the community
}

Ines Testoni

Universita degli Studi di Padova

Fabio Vito Sblano

Universita degli Studi di Padova

Lorenza Palazzo

Universita degli Studi di Padova

Sara Pompele

Universita degli Studi di Padova

Michael Alexander Wieser ( $\nabla$ michael.wieser@aau.at )

Alpen-Adria-Universitat Klagenfurt https://orcid.org/0000-0002-1246-0456

Research article

Keywords: Hospice, Palliative care, Death education, Adolescents, Suicide.

Posted Date: October 18th, 2019

DOI: https://doi.org/10.21203/rs.2.16203/v1

License: (9) This work is licensed under a Creative Commons Attribution 4.0 International License.

Read Full License 


\section{Abstract}

Background The theme of death in Western society has been removed from everyday life and replaced with specialized medical language. Such censorship does not reduce the fear of death, especially among young people, and it limits the possibility to elaborate on experiences linked to death, generating negative effects, especially in cases of traumatic grief. The objective of this follow-up study was to detect how and if experiences of death education changed the relationship between the community and a local hospice in relation to the theme of death and to the elaboration and management of suicide. Methods This was a qualitative research study based on semi-structured interviews with palliative care professionals and teachers of students who had taken part in a death education intervention 3 years earlier. The interviews were examined through thematic analysis. Results The results confirmed the efficacy of the death education intervention initiated 3 years earlier. The education initiative contributed to modifying the students' and teachers' perspectives of end-of-life professionals and their understanding of the structures within which palliative care is implemented. It also modified the participants' perspectives on the representation of death and promoted a new outlook on life. The hospice staff also perceived a change in the attitudes of the community, and this change had a positive impact on their everyday work. Conclusions This study confirmed the usefulness of creating continuity between a hospice and the community through a school education initiative. The death education project provided an educational space in which it was possible to elaborate on experiences linked to death and to re-evaluate and appreciate the structures of end-of-life care and the professionals who work in the area. Keywords: Hospice, Palliative care, Death education, Adolescents, Suicide.

\section{Background}

The theme of death in Western society has been removed from everyday life and replaced with specialized medical language. On the one hand, this can be attributed to medical progress, which has eradicated many once life-threatening illnesses, thereby removing fear of infections and contagions. On the other hand, it may be related to the innate tendency of people to avoid anything that reminds them of their finitude [1]. As affirmed by Terror Management theory, awareness of death is inevitable, and such awareness may occur at any moment for uncontrollable reasons and generate a feeling of latent and constant terror [2]. Anguish linked to death can be managed through supportive cultural systems, which may include symbolic practices, allowing us to envisage salvation after death $[3,4]$. However, these systems are fragile and may be undermined by mortality salience elicited by the reality of everyday life and by mass media constantly sensationalizing and describing death in an unrealistic way [5-8]. One of the most evident examples of this type of denial can be seen in stigmatization of those who work in funeral homes or morgues $[9,10]$ as well as those who work in hospices. Such stigmatization is due to people's inability to identify with these professionals, who are isolated from community life as a result and sufferer increased levels of stress [11 - 13]. This form of social censorship contributes to a reduced awareness of finitude among people and decreased cooperation and solidarity, both of which are needed for authentic human relations. 
Young people are bombarded by media messages that sensationalize death, and they are surrounded by adults who are incapable of addressing the topic in their daily lives [14 - 16]. In truth, this type of censorship does not reduce fear or anxiety related to death [17]. Furthermore, it restricts the possibility of developing a symbolic language to elaborate the experiences that accompany terror surrounding death [17]. The latter can give rise to negative effects, especially in the case of traumatic grief [17].

In light of the aforementioned issues, we developed a death education intervention with 138 students (males, $n=63$; females, $n=75$ ) of three high schools in a town in the South of Italy, focusing on their experiences of traumatic grief caused by the death, by suicide, of one of their school mates. The main hypothesis of the death education intervention was that adolescents who participated in death education experience would express their emotions better, with a higher sense of control over their death imagery and death anxiety $[18,19]$. This was based on the conviction that death education is useful in creating a debate in which to explore the various ways of conceptualizing death, to lead to a greater understanding and clarification of personal value systems. The death education intervention was divided into two parts. In the first part, meditation, psychodrama, and moviemaking were used to reflect upon the meaning of death, spirituality, and transcendence and upon the meaning of suicide. In the second part, the students visited a local hospice, where they had the opportunity to discuss the forms of dying with the hospice staff, how the patients were supported by the team of palliative care, and how their families handled their grief. The intervention produced very positive results [20]. Subsequently, an intervention was designed in conjunction with the municipality, hospice, and local high schools. The intervention drew on a previous model based on experiences of death education [21]. It also drew on the World Health Organization's (2017) definition of palliative care. The main objective of the intervention was to encourage young people to consider the generosity of those who work with competence and passion to enhance and improve the quality of life of those who must die. The intervention highlighted that life was a precious gift, which must be safeguarded, although this did not mean denying death (or prolonging or accelerating it). The discussion path considered how having to face the death of a loved one caused relatives and friends to consider huge existential questions. The team of professionals who took part in the intervention comprised psychologists who were experts in death education, experts in religious sciences, and palliative care doctors and nurses working in the local hospice.

The present study investigated the effects of this experience 3 years later on the participants (teachers/hospice staff) who had taken part in the original intervention.

\section{Methods}

\section{Participants}

The study involved 20 individuals: 11 members (males, $n=5$; females, $n=6$ ) of a local hospice aged between 29 and 50 years $(\mu=44 ; \sigma=5.98)$ and nine school teachers aged between 29 and 63 years $(\mu=$ $48.1 ; \sigma=9.18$ ). The hospice staff comprised two psychologists, three doctors, four nurses, a family liaison officer, and a spiritual guide. Among the hospice staff, $70 \%$ of individuals were university 
graduates, 8 of 11 individuals married/cohabiting, and 9 of 11 individuals had children. All the interviewees were Italian citizens.

The teachers who took part in the intervention were staff members of local schools in the same town where the original study took place. The schools were as follows: two classical lyceums, a scientific lyceum, a European linguistic lyceum, an Upper Secondary Educational Institute and a linguistic lyceum. In the study group, $90 \%$ of the participants were teachers who taught humanistic classes (religion, history, and Italian), and their ages ranged between 31 and 63 years $(\mu=53,11 ; \sigma=10,20)$. All the teachers were university graduates and possessed Italian citizenship (Table 1).

As the students who had participated in the original intervention had finished their studies, they could not be included in the present research, and they could not be traced, as their anonymity was assured in the original intervention.

Each participant was asked to sign an informed consent form authorizing their participation, the data treatment, and the audio-recordings of the interviews. The study was approved by the ethics committee for psychological research of the University of Padova, Italy.

\section{Data collection and analysis}

The study followed qualitative research methodology based on thematic analysis [22, 23] which focuses on the recognition of meanings and concepts [24,25]. To develop a conceptual framework for understanding how the community experienced and made meaning of the death education experience, the thematic analysis shed light on patterns in the dataset [26].

In accordance with the CORE-Q checklist [27] and thematic analysis, the study was partially theory driven, as studies on the ontological representation of death guided the exploration of the data $[28,29]$.

Therefore, the process was based on both a-prior categories (with regard to the representation of death) and categories that only became clear as the analysis progressed (with regard to the effects of the death education experience) $[21,30]$. Six main phases characterized the process: preparatory organization, generation of categories or themes, coding data, testing emerging understanding, searching for alternative explanations, and writing up the report [31].

The interviews were conducted in settings that were familiar to the participants. The mean duration of each interview was 60 minutes. In the interviews, the participants were asked about how they considered that the project had changed perceptions among the community. The interviews were analysed using ATLAS.ti software (Berlin, Germany), which we used to apply codes to text segments. These codes were then combined into "code families" from which the main thematic areas emerged. Networks were also created to highlight logical relations among the identified thematic areas. 


\section{Results}

Based on the responses of the participants, three main thematic areas emerged: (1) changes following the death education intervention, (2) the usefulness of the death education intervention in terms of the elaboration of traumatic grief in the community, and (3) motivations to reintroduce the death education intervention..

\section{Thematic area 1: Changes following the death education intervention}

Some participants reported that the theme of death was not novel, as the traumatic grief that surrounding a student's suicide had previously forced the community to ask questions about the issue of youth suicide. Caterina, one of the teachers, stated that "It was like seeing a person disappear overnight, not being able to convince oneself that everything was over. We feel that the person will return and that he/she has gone away only for a moment."

The experience of reflecting upon the meaning of dying enabled an exploration of ontological representations of death, as elaborated upon by Andrea, one of the hospice nurses:

The course of death education allowed me, in the first place, to examine the ontological representations I had concerning death and, while reflecting upon them, to modify the most distressing ones. Initially, I saw death as something to avoid, something I preferred not to think about, that I preferred to cast aside, and now, instead, I am able to face the idea of death in a calmer way, I am able to speak about it, to mention it; I am able to accept death as, indeed, the conclusion of a path that is part of life. This allows me to act as a support for the patients' relatives in the hospice and also as a support for my own relatives and friends.

For many of the hospice staff, understanding the meaning of the term passage and being able to question it was important, as Andrea emphasised:

I reconsidered my ideas of death, and now I do not consider death as the end of something but rather as a passage. The more I felt that death represented a crossing, the stronger I felt and the more my view concerning life changed too: the idea of life as a succession of experiences that were preserved after death also became stronger.

Lucio, one of the nurses, stressed:

My personal approach to the little things in everyday life has radically changed: I felt more enriched, just waking up in the morning and going to bed in the evening. I was definitely more aware of the fact that all the little things in life should be appreciated. As regards my approach to life, I certainly learned to transform my fear of dying into a desire to live.

According to Giancarlo, one of the teachers, the intervention gave him: 
Participation in the project confirmed that death does not paralyze life, quite the opposite. I could explain this through this metaphor: there is a room, and there are two doors, or better, a revolving door, and life is exactly at the border of these two dimensions. So, I could say that the effect was that I became more aware of my own way of seeing life and death rather than actually changing the way I relate to life.

Some teachers reported that they perceived a change in their students concerning their way of seeing life: Michela, one of the teachers, affirmed:

The students understood that each moment and simple things like a hug or a smile to a person who was suffering, that is, being there, present, was beyond words. I could see that the kids had grown up: the narratives of other experiences made them feel much closer to one another and part of the great mystery of life.

The teachers reported that they experienced feelings they had not prior to their participation in the intervention. Giulio, another teacher, stated that he experienced a paradox:

Talking about the meaning of death, which is the last experience in human life before eternal life, has contributed to make more meaningful and truer my everyday life. In this way, I certainly learned to grasp nuances in life that perhaps I took for granted before. Because of this, I learned to value life itself even more.

There was a shift in how the community viewed the hospice (end-of-life care) and hospice staff after the death education project. Prior to the project, the hospice and hospice staff were surrounded by an aura of mystery and fear because of prejudice on the part of the community (i.e., social censorship). Giulio affirmed:

The general fear was of entering a sort of "factory of death." When I proposed to visit the hospice, the students were full of prejudices that certainly came from what we, as adults, communicate to them, from the way in our society we talk about the hospice.

All the teachers stressed the usefulness of the intervention in overthrowing these prejudices, as Caterina affirmed:

The intervention has served to break down barriers, various prejudices concerning the hospice, and I must say I keep talking about it fondly; the idea of dying at the hospice, with all the people I love close to me, has made me rethink and revaluate the concept of this place, and now I see it as a place full of dignity. Before this experience, I knew nothing about the work of end-of-life professionals, I did not have any kind of experience in this field. I have often worked in close contact with people suffering and marginalized in the past, but I did not know there were personnel qualified in end-of-life care. And I must say I found this particularly impressive.

Giancarlo (teacher) affirmed: 
The students had faith in this course and in the end, they changed their opinion, and they also talked about this experience at home and with their friends. Thanks to the themes addressed during this path, their fears and anguish declined. This allowed the students to delve deep into themselves and better understand their emotions.

Please insert Figure 1 about here.

\section{Thematic area 2: Usefulness of death education for the elaboration of traumatic grief in the community}

In relation to the elaboration of traumatic grief, almost all the hospice staff and the professors expressed the concept in very positive terms. Valeria, a psychologist at the hospice, affirmed:

There is a huge difference between being silent, as often happens after a suicide, and being able to talk about it, considering death as something natural. In the latter case, the elaboration of grief helps people draw on resources they need to face the situation and the distress, without isolating themselves, but on the contrary talking about grief at the community level offers support to all.

Fabio, a doctor, declared:

Talking about death can make us reflect upon the fact that death is part of life and that therefore it is not something obscene but rather something that is natural. It is important to intervene with a philosophical reflection concerning life, considering it a good that is not endless, but on the contrary available for a limited amount of time.

Many of the teachers also had a very positive view of the death education intervention. Rosaria stated:

A student of mine had suffered a great loss but, thanks to this intervention, he could go on with his life, elaborating on his grief, and this allowed him to get through it peacefully and calmly. This intervention was fundamental because it allowed us to understand that life, which ends with death, is made of steps that are very satisfying but also of other steps that are made of intense suffering. So, a life without suffering is not possible, but it is not necessary either; by eliminating loneliness and involving people in social relationships within the community, suicide can be prevented.

Matteo, a doctor in the hospice, expressed the following sentiments:

The course of death education could be reintroduced because from the palliative doctor's point of view or from the point of view of the end-of-life care staff who are striving to create a network between themselves and the community, I think this is one of the most important and fundamental ways to change our culture concerning end-of-life care. It would be a Copernican revolution if we could improve the life quality and well-being of people and of community. This would certainly result in a more mature approach to death.

Among the nurses Lucio said: 
Death education is useful because it means going back to our origins; in the past, indeed, when there wasn't a very sophisticated health network, these paths to accompany people facing death were conducted at home, and therefore there was much more solidarity. A communitarian path would help rediscover what we already have inside of us, that is, the importance of accompanying a person right until his/her last instant of life. Thanks to these death education paths, there is a more welcoming atmosphere in the hospice, and the sense of responsibility towards the patients and their families increased, because we now operate in a cultural environment that needs to seriously deepen the themes of death.

The teachers' declarations on the usefulness of death education at the community level appeared to be just as positive as those of the hospice staff. In some cases, they favoured a proactive approach, with some putting forward innovative proposals to facilitate death education in schools, parishes, and city squares. Antonio one of the teachers, affirmed:

It would be useful especially because of the psychological help the patients' relatives could receive, but also because it would promote human growth: everyone could become aware of the fact that every one of us will one day live the experience of death.

Please insert Figure 2 about here.

\section{Thematic area 3: Motivations to reintroduce the death education intervention}

The psychologist Valeria declared that "The educational, pedagogical, and formative power inherent in this intervention might help people understand that sooner or later they will have to handle separation, loss, and illness." According to Catia, who was the family liaison officer, a similar intervention should be proposed again:

From a professional's point of view, it would help those who are part of the palliative care team, like us, to reformulate and reconsider our knowledge and competencies, as well as what we think we have learned, which can be questioned precisely thanks to the discussion with the students.

According to Rosaria (teacher):

On a personal level, I believe that a intervention like this one has a lot to offer because it allows the teacher to enter into a relation with other teachers, and it allows us to break through barriers with the students, so that we do not rigidly distinguish between the teacher and the student, and this is very worthwhile. I think it is a way to grow up together.

Both the teachers and hospice personnel reported that they believed that the students would welcome the reintroduction of the intervention. Catia stressed:

For the students, this is certainly an experience to repeat, especially at this age when it is important to start reflecting upon and facing the theme of life and death. Reintroducing this project in schools would 
also be helpful to us as professionals and as parents of adolescent children. I am really frightened by the idea that my children might not be prepared to face death-related events, which may be expected, sudden, or long and painful, like those often associated with a terminal illness.

Luisa, one of the teachers, affirmed:

It would be useful to repeat this experience because we have new students every year, and the intervention could create a cycle of events, with important outcomes. The students had an opportunity to experience something that few, if any, students have today in schools that is, the possibility deal in a serious way with these themes and to be able to approach them both as individuals and as a community.

Catia expressed the main strengths that should be maintained in a future intervention:

One of the main strengths was the multidisciplinary approach, which allowed that students to meet all the hospice staff, even those who might have marginal roles, such as administrative staff. Another strength was the possibility to engage with the students, to take the time to talk to them, and to allow their fears to emerge, together with their anxieties concerning the themes of death and dying. Not even the teamwork should be underestimated: everyone, with his/her own competence, tried to offer the best contribution possible.

According to the cleric Luigi:

The most meaningful part of the intervention was that the students had the opportunity to visit the hospice, which in the eyes of the community represents a place of death and therefore a place to avoid: this experience had a major emotional impact on the students; another important aspect was the interaction between students and different professional figures. In this way, a sort of osmosis occurred. Finally, another meaningful aspect was the contact with the young generation concerning a thematic area that is rarely directly explored.

According to Caterina (teacher), it was important that the intervention be reintroduced:

The encounters with the psychologist were very important: the students, at first, found it difficult to open up, but then, thanks to the psychologist's help, they managed to do so, and certain bad situations between students changed. What impressed me the most is that many of the kids chose me to talk about certain problems they had, or even to talk about their parents' or grandparents' relationship with death and suffering; what surprised me also was that we talked about death in class, whereas they usually asked me to talk about it outside of class time. Seeing kids who normally hang around in small groups all coming together was amazing.

Along the same lines, Giulio, a teacher, stated "Another positive aspect emerged concerning the capability to resolve certain critical situations that were present in the classes, like arguments and discussions, and it was possible to build more empathy among the students." 
Please insert “Figure 3 about here.

\section{Discussion}

The objective of this study was to explore how the relationship between the community and a local hospice changed following a death education intervention based on an analysis of the themes of death, dying, and suicide and to evaluate the efficacy of a death education intervention 3 years after its introduction in the local schools.

The analyses of the interviews revealed three main themes and highlighted that the death education intervention had produced meaningful changes. The analysis also confirmed that the death education intervention had a wide positive effect on students, teachers and the hospice staff. The first major theme was a change in representations of death, the attitude towards life, and perspectives concerning the hospice and palliative care. This intervention modified their perspectives concerning the work of end-oflife professionals and the structures in which palliative care is implemented. It also emphasized that the last moments of life can be a time of serenity, with the patient's dignity and respect of paramount importance. The process of reconstructing the meaning of dying allowed teachers to reflect together with the adolescents upon the meaning of the valorisation of life [20,32]. The participants' (both teachers and the hospice staff) perspectives on death education confirmed the findings in the literature. According to various studies, death education can be considered an important component of a school's curriculum by promoting positive attitudes towards life and reflection upon existential themes [33,34]. The intervention proved useful by eliminating various barriers and cultural prejudices, promoting a shift of perspective concerning the hospice and palliative care. This intervention promoted a change in the teachers' perspective and, in their perception, also in students' ones with respect to the hospice and the work of the hospice staff, reducing their prejudices towards hospices and staff in palliative care settings [35].

The death education experience in the hospice facilitated the elaboration of the suicide committed by a student. Many of the interviewees stressed that the possibility to talk about death and to discuss themes related to death stimulated the students to reflect upon the value of life and the importance of respecting its fragility. Such behaviours may be linked to a fascination with death that young people may have based on the belief that it will free them from anxieties [36]. The scientific literature supports the idea that a mature concept of death may prevent risky behaviours by valuing life $[16,37]$. Death education interventions, which aim to increase social support, optimism, and spirituality through specific strategies of adaptive coping, can promote post-traumatic growth among those who have to deal with sudden grief [38 - 41]. The participants (both teachers and the hospice staff) stressed that the death education project served as a bridge to education among the whole community. Furthermore, they appeared interested in repeating the experience in the future. The introduction in high schools of a similar death education intervention appears worthwhile, as is allowed the professionals to improve their knowledge and competences in their everyday work, similarly to other professional updates aimed to increase healthcare relational competencies [42 - 45]. The hospice staff stated that this intervention allowed them to improve both their teamwork skills and their knowledge concerning themes related to death education. It also 
enabled them to have a more positive attitude towards the provision of assistance to the terminally ill and their families, as previously described in the literature [46 - 48].

The teachers reported that they appreciated the possibility to visit the hospice and to have discussions with experts in palliative care. They considered their encounters very meaningful experiences. The professionals working in this specific healthcare field represented a privileged point of view from which to talk to the students about death, and they had the perception that the students could perceive the professionals as simple human beings, not omniscient nor omnipotent, removing the aura of mystery and terror linked to themes related to death [49-51].

One of the main limitations of the present study was that did not involve the students who took part in the original project. In future studies, it would be desirable to activate a higher number of follow-ups of these death education interventions to assess their efficacy after some time and extend the existing literature regarding the practices of death education for adolescents.

\section{Conclusions}

This study confirmed the usefulness of creating continuity between the hospice and the community through a school death education intervention. The present follow-up was conducted 3 years after the intervention and applied qualitative methodology. It demonstrated the efficacy of the death education intervention and identified meaningful changes among the teachers in the intervention in terms of the representation of death and their approach to life, as well as their perceptions of the structures of end-oflife, with these perceptions changing in a positive way. Hospice staff members also perceived a positive change towards them on the part of the community. The intervention had many positive aspects. In particular, the continuity between the hospice and schools engendered a psycho-educational space in which the students could explore their fears and worries surrounding death. This space allowed the students and adults to elaborate on the grief caused by a student's suicide, allowing them to consider death without dread and to explore emotions that are usually concealed. The death education experience improved the moral environment of the schools and contributed to community building An extremely positive outcome was that that the students themselves had played an active role in the change in the community.

\section{Declarations}

\section{Ethics approval and consent to participate}

The study was approved by the ethics committee for psychological research of the University of Padova, Italy (No. B9A50488FF46457ADE1F0F9A4FC5760E)

\section{Consent for publication}

Not applicable. 
Availability of data and materials

The datasets analysed during the current study are not publicly available due to the large amount of interviews analysed but are available from the corresponding author on reasonable request.

\section{Competing interests}

The authors declare that they have no competing interests.

\section{Funding}

The authors received no financial support for the research, authorship, and/or publication of this article.

\section{Authors' contributions}

All authors have approved the manuscript for submission. All authors contributed to the study conception and design. Material preparation, data collection and analysis were performed by IT, FVS, LP, SP and MW. The first draft of the manuscript was written by IT and all authors commented on previous versions of the manuscript. All authors read and approved the final manuscript.

\section{Acknowledgments}

Not applicable.

\section{References}

1. Testoni I, Piscitello M, Ronconi L, Zsák É, lacona E., Zamperini A. Death Education and the Management of Fear of Death Via Photo-Voice: An Experience Among Undergraduate Students. Journal of Loss and Trauma. 2019.

2. Solomon S, Testoni I, Bianco S. Clash of civilizations? Terror management theory and the role of the ontological representations of death in contemporary global crisis. Test. Psychom. Methodol. Appl. Psychol. 2017;24:379-398.

3. Testoni I, Visintin EP, Capozza D, Carlucci MC, Shams M. The implicit image of God: God as reality and psychological well-being. Journal for the Scientific Study of Religion. 2016a;55(1):174-184.

4. Testoni I, Bingaman K, Gengarelli G, Capriati M, De Vincenzo C, Toniolo A, Marchica B, Zamperini A. Self-Appropriation between Social Mourning and Individuation: a Qualitative Study on Psychosocial Transition among Jehovah's Witnesses. Pastoral Psychology. 2019;1-17.

5. Gilbert KR, Murray Cl. The family, larger systems and death education, in Handbook of Thanatology, ed D. Balk. London: Routledge. 2007. p.345-353.

6. Noppe IC. Historical and contemporary perspectives on death education. In D. Balk (Ed.), Handbook of thanatology. London: Routledge. 2007a. p. 329-335. 
7. Noppe IC. Life Span issues and death education. In D. Balk (Ed.), Handbook of thanatology. London: Routledge. 2007b. p. 337-343.

8. Testoni I, Facco E, Perelda F. Toward A New Eternalist Paradigm for Afterlife Studies: The Case of the Near-Death Experiences Argument. World Futures. 2017;73(7):442-456.

9. Thompson WE. Handling the stigma of handling the dead: Morticians and funeral directors. Deviant Behavior. 1991;12(4):403-429.

10. Thomson SB, Grandy G. Stigmas, Work and Organizations. Basingstoke, England: Springer. 2017.

11. Ashforth BE, Kreiner GE, Clark MA, Fugate M. Normalizing Dirty Work: Managerial Tactics For Countering Occupational Taint. Academy of Management Journal. 2007;50(1):149-174.

12. Ashforth BE, Kreiner GE. "How Can You Do It?": Dirty Work and the Challenge of Constructing a Positive Identity. The Academy of Management Review. 1999;24(3): 413.

13. Sardiwalla N, VandenBerg H, Esterhuyse KGF. The Role of Stressors and Coping Strategies in the Burnout Experienced by Hospice Workers. Cancer Nursing. 2007;30(6):488-497.

14. Adams DW. Children, adolescents and death: myths, realities and challenges. Death Studies. 1999;23(5):443-463.

15. Butler J. Precarious Life: The Powers of Mourning and Violence. London: Verso. 2004.

16. Testoni I, Parise G, Zamperini A, Visintin EP, Toniolo E, Vicentini S, De Leo D. The "sick-lit" question and the death education answer. Papageno versus Werther effects in adolescent suicide prevention. Human Affairs. 2016;26(2).

17. Testoni I. Psicologia del lutto e del morire: Dal lavoro clinico alla death education [The psychology of death and mourning: From clinical work to death education]. Psicoterapia e Scienze Umane. 2016;50(2):229-252.

18. Kastenbaum R. Death, Society, and Human Experience (8th Edn) Boston, MA: Pearson. 2004.

19. Currier JM, Holland JM, Neimeyer RA. Making sense of loss: acontent analysis of end-of-life practitioners' therapeutic approaches. OMEGA - Journal of Death Dying. 2008;57:121-141.

20. Testoni I, Ronconi L, Palazzo L, Galgani M, Stizzi A, Kirk K. Psychodrama and moviemaking in a death education course to work through a case of suicide among high school students in Italy. Frontiers in Psychology. 2018;9:441.

21. Testoni I, Ronconi L, Cupit IN, Nodari E, Bormolini G, Ghinassi A, Messeri D, Cordioli C, Zamperini A. The effect of death education on fear of death amongst Italian adolescents: A nonrandomized controlled study. Death Studies. 2019;1-10.

22. Braun V, Clarke V. Thematic analysis. In Cooper H, Camic PM, Long, Panter AT, Rindskopf D, Sher KJ (Eds.). APA handbook of research methods in psychology, Vol 2: Research designs: Quantitative, qualitative, neuropsychological, and biological. Washington, DC: American Psychological Association. 2012. p. 57-71.

23. Testoni I, Russotto S, Zamperini A, De Leo D. Addiction and religiosity in facing suicide: A qualitative study on meaning of life and death among homeless people. Mental Illness. 2018;10(1):16-24. 
24. Zamperini A, Testoni I, Primo D, Prandelli M, Monti C. Because Moms Say So: Narratives of Lesbian Mothers in Italy. Journal of GLBT Family Studies. 2016;12(1):91-110.

25. Zamperini A, Paoloni C, Testoni I. The emotional labor of nursing: Critical incidents and coping strategies [II lavoro emozionale dell'assistenza infermieristica: Incidenti critici e strategie di coping]. Assistenza Infermieristica e Ricerca. 2015;34(3):142-148.

26. Testoni I, Ghellar T, Rodelli M, De Cataldo L, Zamperini A. Representations of death among Italian vegetarians: An ethnographic research on environment, disgust and transcendence. Europe's Journal of Psychology. 2017;13(3):378-395.

27. Tong A, Sainsbury P, Craig J. Consolidated criteria for reporting qualitative research (COREQ): A 32item checklist for interviews and focus groups. International Journal for Quality in Health Care. 2007;19(6):349-357.

28. Testoni I, Ancona D, Ronconi L. The Ontological Representation of Death: A Scale to Measure the Idea of Annihilation Versus Passage. OMEGA-Journal of Death and Dying. 2015;71(1):60-81.

29. Testoni I, Bisceglie D, Ronconi L, Pergher V, Facco E. Ambivalent trust and ontological representations of death as latent factors of religiosity. CogentPsychology. 2018;5(1).

30. Pope C, Ziebland S, Mays N. Qualitative research in health care. Analysing qualitative data. BMJ. 2000;320(7227):114-116.

31. Marshall C, Rossman G. Designing qualitative research (3rd ed.). London, United Kingdom: Sage. 1999.

32. Neimeyer RA. Death anxiety handbook: Research, instrumentation, and application. New York: Taylor \& Francis. 1994

33. Corless IB, Germino BB, Pittman MA. A Challenge for Living: Dying, Death, and Bereavement. Boston: Jones and Bartlett. 1995.

34. Wass H, Miller MD, Thornton G. Death education and grief/suicide intervention in the public schools. Death Studies. 1990;14(3):253-268.

35. Santos JLD, Bueno SMV. Death education for nursing professors and students: a document review of the scientific literature. Revista da Escola de Enfermagem da USP. 2011;45(1):272-276.

36. Yuko I, Fumie S. Development of Death Attitudes in Puberty and Adolescence, Japanese Journal of Counseling Science, 2008;41(3):213-23.

37. Gould MS, Lake AM, Kleinman M, Galfalvy H, Chowdhury S, Madnick A. Exposure to Suicide in High Schools: Impact on Serious Suicidal Ideation/Behavior, Depression, Maladaptive Coping Strategies, and Attitudes toward Help-Seeking. Int. J. Environ. Res. Public Health. 2018;15(3):455.

38. Gerrish N, Dyck MJ, Marsh A. Post-traumatic growth and bereavement. Mortality. 2009;14(3), 226244.

39. Heath MA, Cole BV. Strengthening Classroom Emotional Support for Children Following a Family Member's Death. School Psychology International. 2012;33(3):243-62. 
40. Schaefer JA, Moos RH. The context for posttraumatic growth: Life crises, individual and social resources, and coping. Posttraumatic growth: Positive changes in the aftermath of crisis. 1998;99:126.

41. Tedeschi RG, Calhoun LG. Posttraumatic Growth: Conceptual Foundations and Empirical Evidence. Psychological Inquiry, 2004;15(1):1-18.

42. de Lima R, Brito Bergold L, de Souza JDF, Genesis B, Ferreira M. Death education: sensibility for caregiving. Revista brasileira de enfermagem. 2018;71(suppl 4):1779-1784.

43. Johansson N, Lally T. Effectiveness of a Death-Education Program in Reducing Death Anxiety of Nursing Students. OMEGA - Journal of Death and Dying. 1991.22(1):25-33.

44. Tamlyn BD. An International Survey of Death Education Trends in Faculties of Nursing and Medicine. Death Studies, 1997;21(2):177-188.

45. Wass H. A Perspective on the current state of Death Education. Death Studies. 2004;28(4):289-308.

46. Frommelt $\mathrm{KH}$. The effects of death education on nurses' attitudes toward caring for terminally ill persons and their families. American Journal of Hospice and Palliative Medicine®. 1991;8(5):37-43.

47. McCorkle RS. Death education for advanced nursing practice. Death Education. 1981;5(4):347-361.

48. Miles MS. The effects of a course on death and grief on nurses' attitudes toward dying patients and death. Death Education. 1980;4(3):245-260.

49. Homedes N, Ahmed SM. In My Opinion...Death Education for Children. Children's Health Care. 1987;16(1):34-36.

50. Leviton D. A course on death education and suicide prevention: implications for health education. Journal of the American College Health Association. 1971;49(4):217-220.

51. Leviton D. The scope of death education. Death Education. 1977;1(1):41-56.

\section{Tables}

Table 1. Demographic variables of the participants 


\begin{tabular}{|c|c|c|c|c|c|c|}
\hline & \multicolumn{2}{|l|}{ Age } & \multicolumn{2}{|l|}{ Sex } & \multicolumn{2}{|l|}{ Qualification } \\
\hline & $\mu$ & $\sigma$ & Female & Male & High-school diploma & University degree \\
\hline School & 53.11 & 10.2 & 6 & 3 & 4 & 16 \\
\hline$(n=9)$ & & & & & & \\
\hline Hospice & 44 & 5.98 & 6 & 5 & 4 & 7 \\
\hline$(n=11)$ & & & & & & \\
\hline Total & 48.1 & 9.18 & 12 & 8 & 0 & 9 \\
\hline$(N=20)$ & & & & & & \\
\hline
\end{tabular}

Figures

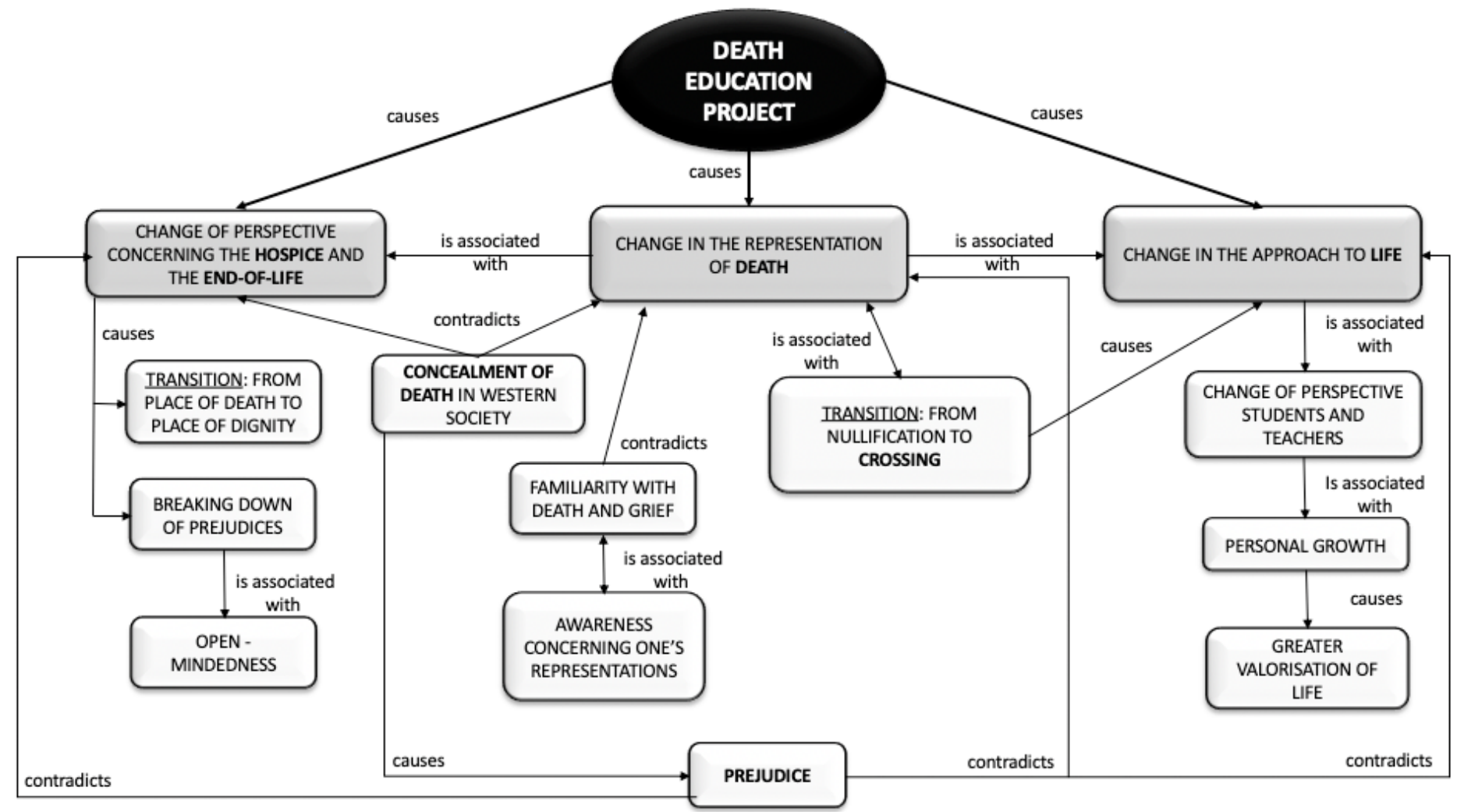

Figure 1 


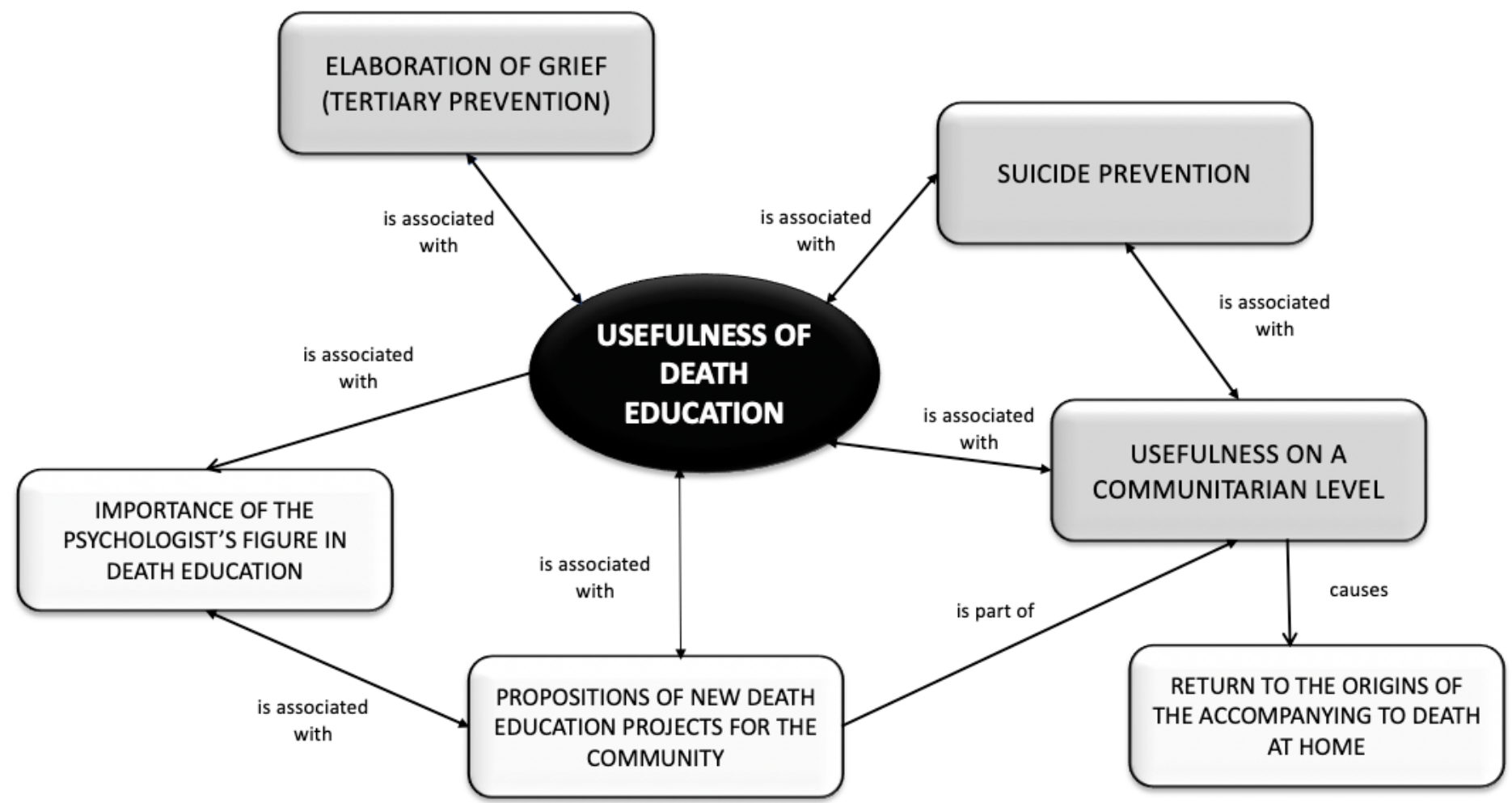

Figure 2

Usefulness of death education

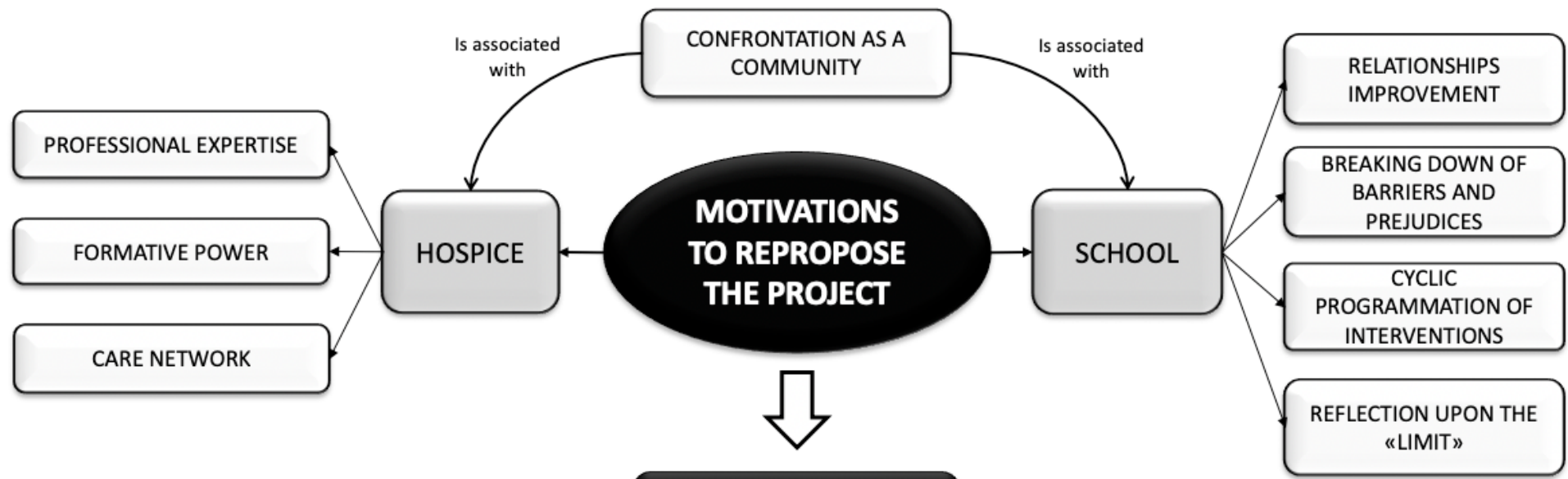

\section{STRENGTHS}

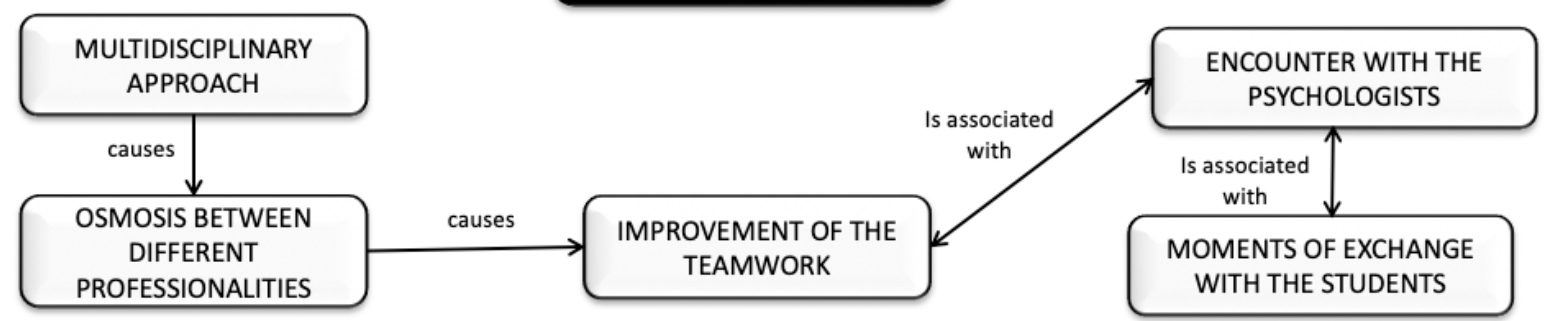


Figure 3

Motivations to reintroduce the intervention 